\title{
PENINGKATAN NILAI KEKERASAN BAJA C-Mn DENGAN METODE QUENCHING DAN TEMPERING
}

\author{
Padang Yanuar \\ Program StudiTeknika \\ STIMART “AMNI” Semarang \\ Email: padang_yanuar@yahoo.co.id \\ Iman Mujiarto \\ Program Studi Teknika \\ STIMART “AMNI” Semarang \\ Email:imnmu@yahoo.com \\ Yoeli Janto \\ Program Studi Nautika \\ STIMART “AMNI” Semarang \\ Email:yoelijanto@yahoo.com
}

\begin{abstract}
ABSTRAK
Perlakuan panas quenching dan tempering telah lama diterapkan pada baja untuk menghasilkan kombinasi antara kekuatan dan ketangguhan yang baik dengan struktur mikro martensite. Sifat baja seperti kekerasan yang tinggi dengan kombinasi ketangguhan yang baik membuat baja menjadi pilihan utama untuk material armor (tahan peluru). Tujuan penelitian ini melakukan kajian perubahan sifat mekanis baja komersial (baja C-Mn) akibat proses quenching dan tempering untuk dapat diaplikasikan sebagai baja armor. Pemanasan pada temperatur austenit $900{ }^{\circ} \mathrm{C}$ dengan penahanan selama 45 menit kemudian dilakukan quenching pada media air dilanjutkan tempering $175^{\circ} \mathrm{C}$ selama 30 menit didapatkan nilai kekerasan tertinggi sebesar 546 BHN dengan dominasi struktur mikro martensite yang terbentuk.
\end{abstract}

Kata kunci: armor, kekerasan, quenching, tempering.

\begin{abstract}
The heat treatment of quenching and tempering has long been applied to steel to produce a combination of good strength and toughness with martensitic microstructure. The high hardness properties of steel with good toughness combine make steel the ultimate choice for armor material. The purpose of this research is to study the change of mechanical properties of commercial steel $(C-M n$ steel) due to quenching and tempering process to be applied as armor steel. Heating at austenite temperature of $900{ }^{\circ} \mathrm{C}$ hold for 45 minutes then quenching on water continued tempering $175 \mathrm{C}$ for 30 minutes obtained the highest hardness value of $546 \mathrm{BHN}$ with the dominant martensitic microstructure formed.
\end{abstract}

Keywords: armor, hardness, quenching, tempering.

\section{PENDAHULUAN}

Penyediaan dan Pemenuhan alat utama sistem senjata (alutsista) Tentara Nasional Indonesia (TNI) tergantung dari produk impor. Impor langsung kendaraan tempur dalam bentuk jadi (Completely Build Up : CBU) dari negara produsen seperti Jerman, Inggris, Prancis dan Rusia, maupun bahan baku berupa plat tahan peluru. Sesuai dengan arah kebijakan anggaran belanja, pengembangan industri pertahanan Indonesia telah ditingkatkan. Dalam Rencana Pembangunan Jangka Panjang Nasional (RPJMN) 2015 2025 bidang pertahanan salah satu arah kebijakan adalah penyediaan dan terpenuhinya alutsista TNI dengan meningkatkan peran industri nasional dalam negeri [1]. PT. Pindad, Indonesia, selaku produsen peralatan militer dalam negeri telah menghasilkan kendaraan tempur yang diakui dunia internasional, yaitu Anoa 6 x 6 dan Komodo 4 x 4 [2].

Baja sebagai bahan armor (tahan peluru) masih menjadi pilihan utama untuk dikembangkan karena mudah diproses, dilas dan dapat digunakan sebagai stuktur utama serta sekaligus sebagai pelindung tahan peluru [3]. Baja yang dirancang untuk mampu menahan tembusan proyektil yaitu baja dengan kekerasan 
dan kekuatan tinggi (kekerasan semakin tinggi semakin baik) [4]. Pengembangan material tahan peluru (armor, armour) telah banyak dilakukan melalui penemuan material baru, pemaduan komposisi, perlakuan panas, pelapisan permukaan dan pembuatan komposit baik dari dari bahan logam maupun nonlogam [5].

Perlakuan panas diberikan pada baja untuk menghasilkan sifat-sifat yang diinginkan. Perlakuan panas diawali dengan proses austenisasi (pemanasan hingga temperatur austenite) yang kemudian disusul pendinginan dengan beragam kecepatan pendinginannya yang akan menghasilkan fasa akhir yang terbentuk berbeda-beda. Dengan pendinginan yang lambat akan terbentuk struktur mikro pearlite dan lapisan tipis feritsementit, ditingkatkannya laju pendinginan akan mengurangi ketebalan lamela dan jika ditingkatkan lagi akan membentuk struktur mikro bainit, laju pendinginan yang sangat cepat akan menghasilkan struktur mikro martensite [6]. Diagram transformasi yang mungkin terjadi melalui dekomposisi austenite ditunjukkan pada Gambar 1.

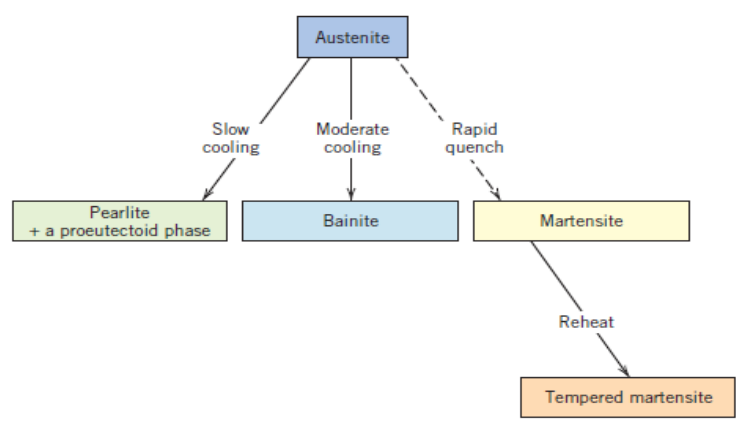

Gambar 1. Transformasi Austenite [6]

Pada penelitian ini bertujuan melakukan kajian perubahan sifat mekanis baja komersial (baja C-Mn) akibat proses quenching dan tempering. Hasil yang ingin didapatkan pada penelitian ini adalah parameter perlakuan panas guna mendapatkan baja C-Mn yang dapat diaplikasikan sebagai baja tahan peluru.

\section{METODOLOGI PENELITIAN}

Baja yang digunakan pada penelitian ini adalah baja C-Mn dengan ketebalan $10 \mathrm{~mm}$, langkah langkah penelitian dapat dilihat pada gambar 2 .

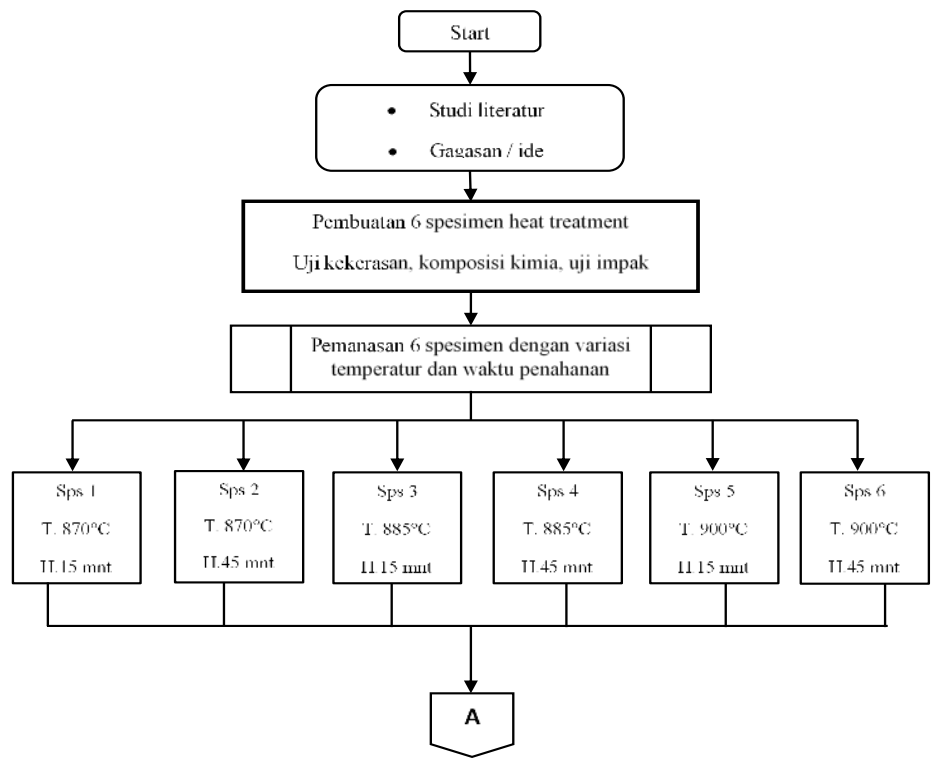

Gambar 2. Diagram Alir Penelitian 


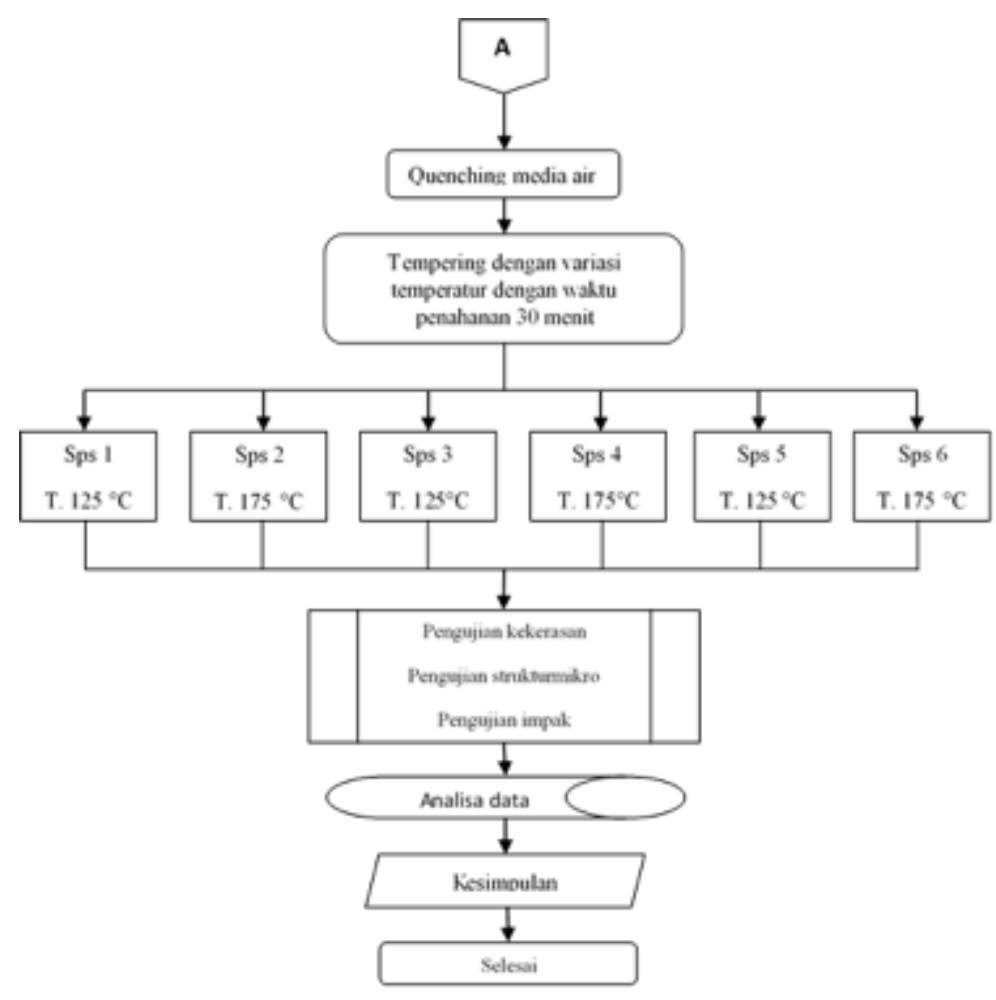

Gambar 3. Lanjutan Diagram Alir Penelitian

\section{HASIL DAN PEMBAHASAN}

\subsection{Pengujian Komposisi Kimia}

Komposisi kimia dari baja C-Mn dapat dilihat pada tabel 1. Pengujian komposisi kimia dilakukan untuk mengetahui unsur-unsur apa saja yang terkandung di dalam baja, dilakukan dengan menggunakan alat uji Optical Emission Spectrometer Machines ARL type 3460.

Tabel 1. Komposisi kimia baja C-Mn

\begin{tabular}{lllllllll}
\hline Unsur & $\boldsymbol{C}$ & $\boldsymbol{M n}$ & $\boldsymbol{S i}$ & $\boldsymbol{P}$ & $\boldsymbol{S}$ & $\boldsymbol{C r}$ & $\mathbf{M o}$ & $\boldsymbol{N i}$ \\
\hline \%Berat & 0,293 & 1,41 & 0,329 & 0,01 & 0,003 & 0,55 & 0,193 & 0,278 \\
\hline
\end{tabular}

Dilihat dari unsur-unsur kimia yang terdapat pada baja C-Mn dapat digolongkan kedalam baja paduan rendah dimana unsur-unsur penambah yang lain $\leq 8 \mathrm{wt} \%$, unsur-unsur pemadu yang lain digunakan untuk mendapatkan sifat mekanik yang diperlukan. Unsur C yang tinggi akan meningkatkan fraksi volume dari austenite setelah quenching, akan meningkatkan kekerasan dari martensite. Unsur Mn meningkatkan kemampu kerasan dari baja unsur Si meningkatkan ketahanan korosi menurunkan jarak kisi dari matrik ferit menunda penguraian martensite dan transisi karbida pada saat tempering. Unsur $\mathrm{Cr}$ Sangat efektif dalam memperlambat pelunakan $\mathrm{Fe}_{\mathrm{a}} \mathrm{C}$ dalam proses tempering dengan membentuk $M_{2} C$, unsur Ni solid solution hardening, dengan $\mathrm{Cr}$ menghasilkan baja paduan dengan kemampuan kekerasan tinggi, ketahanan impak dan fatik yang tinggi. Unsur Mo hanya untuk mensteable $\mathrm{Mo}_{2} \mathrm{C}$, dapat meningkatkan kekerasan dengan proses tempering disekitar $500^{\circ} \mathrm{C}$.

\subsection{Pengujian Kekerasan}

Hasil pengujian kekerasan ditampilkan pada gambar 4, dalam kondisi quench bahan memiliki batas kekuatan dan kekerasan tertinggi namun keuletannya terendah dan sejumlah besar distorsi terjadi selama pembentukan martensite yang mengarah ke peningkatan kekuatan dan kekerasan [8]. 


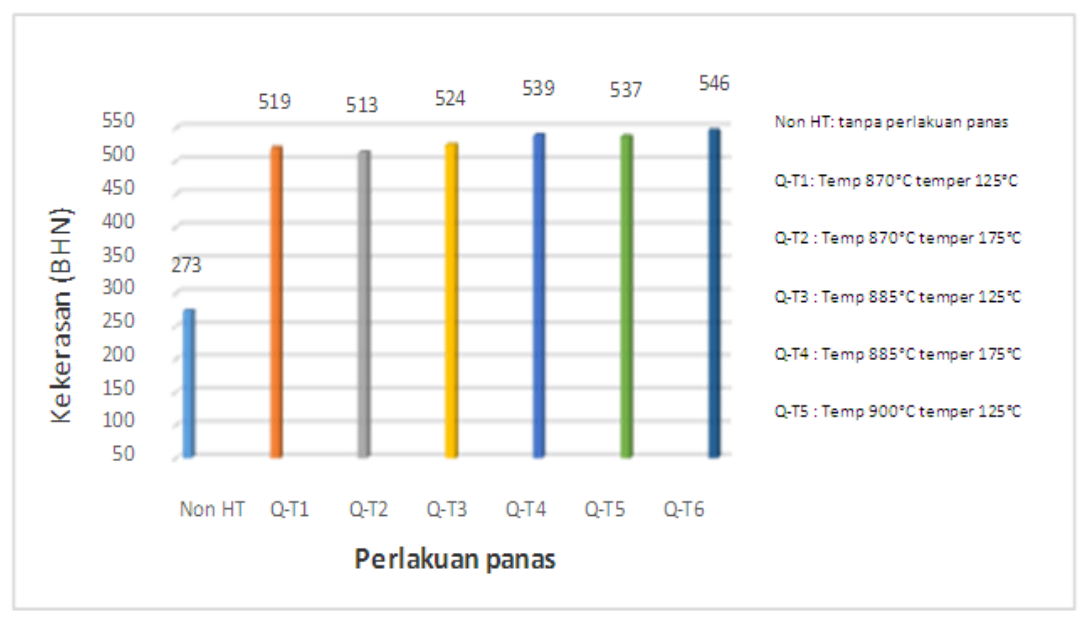

Gambar 4. Nilai Kekerasan Baja Hasil Quench Dan Temper

Baja setelah proses quenching didapatkan struktur mikro martensite yang mempunyai sifat yang keras namun rapuh, untuk meningkatkan nilai kekuatan dan keuluten dari baja dilakukan proses tempering dengan temperatur diantara $250^{\circ} \mathrm{C}-600^{\circ} \mathrm{C}$ [9], pada saat pemanasan martensite akan membentuk $\mathrm{Fe}_{\mathrm{a}} \mathrm{C}$ dan karbida dalam matrik ferit. Perubahan struktur mikro ini yang secara bertahap akan menurunkan kekerasan dan kekuatan luluh namun akan meningkatkan keuletan dan ketangguhan. Untuk kondisi temperatur tertentu atau temperatur yang rendah tidak akan mempengaruhi nilai kekerasan, pada temperatur dibawah $200^{\circ} \mathrm{C}$ akan menghilangkan tegangan dalam terlebih dahulu [6]. Hasil perlakuan panas memperlihatkan peningkatan nilai kekerasan setelah dilakukan proses quenching dan tempering dibandingkan dengan logam dasar baja C-Mn. Peningkatan temperatur austenite meningkatkan nilai kekerasan baja C-Mn. Nilai kekerasan tertinggi didapatkan pada pemanasan temperatur $900{ }^{\circ} \mathrm{C}$ dan dilanjutkan tempering pada suhu $175^{\circ} \mathrm{C}$ yaitu sebesar $537 \mathrm{BHN}$.

\subsection{Pengujian Struktur Mikro}

Mikrografi menghasilkan gambar-gambar seperti terlihat pada gambar 5a,b,c, dan d, diambil dengan pembesaran 100X. Gambar 5a adalah struktur mikro baja sebelum dilakukan proses quenching dan tempering terlihat struktur mikro yang berbentuk pipih memanjang yang diakibatkan dari proses pembuatan baja C-Mn yang dilakukan proses pengerolan, struktur mikro berwarna terang (ferrite) mendominasi dari baja C-Mn yang menyebabkan baja memiliki sifat lunak tetapi ulet dan struktur yang lain adalah struktur yang berwarna gelap (pearlite), gambar 5b menunjukan spesimen yang dilakukan proses quenching dipanaskan pada temperatur austenite $870^{\circ} \mathrm{C}$ terlihat perbedaan antara struktur mikro dengan baja dasar terlihat struktur mikro martensite yang ditandai seperti berbentuk jarum-jarum kecil yang tersusun secara tidak teratur, terbentuknya struktur martensite ini yang menyebabkan baja mengalami kenaikan kekerasan bila dibandingkan dengan logam dasar C-Mn yang tidak dilakukan proses quenching. Martensite sangat keras dan juga sangat rapuh sehingga tidak dapat digunakan di sebagian besar aplikasi, setiap tekanan internal yang telah diterapkan selama pendinginan memiliki efek melemahkan. Keuletan dan ketangguhan material dapat ditingkatkan dengan perlakuan panas yang disebut tempering yang membantu melepaskan tekanan internal. Gambar 5c dan 5d adalah baja C-Mn yang telah dilakukan proses quenching dilanjutkan tempering masih terlihat jelas struktur mikro martensite dengan susunan yang masih acak dan kasar, tempering pada suhu dibawah $200{ }^{\circ} \mathrm{C}$ tidak berpengaruh banyak pada penurunan nilai kekerasan, hal ini disebabkan karena sebagian martensite mengalami difusi.

\subsection{Pengujian Fraktografi}

Pengamatan permukaan patahan hasil pengujian impak dilakukan untuk membandingkan jenis patahan yang terjadi pada baja $\mathrm{C}$-Mn sebelum maupun setelah dilakukan proses quenching dan tempering. Gambar 6 menunjukan hasil patahan baja dasar C-Mn terlihat bentuk patahan yang identik dengan bentuk patahan ulet karena bentuk patahan penampang nampak tertarik keluar / patah ulet ini ditandai dengan penyerapan energi disertai adanya deformasi plastis yang cukup besar di sekitar patahan sehingga permukaan patahan nampak kasar, berserabut (fibrous) (a dan b), sedangkan gambar 7A dan 7B 
terlihat patah getas ditandai dengan bentuk permukaan yang rata dan tidak ada reduksi luas penampang patahan.
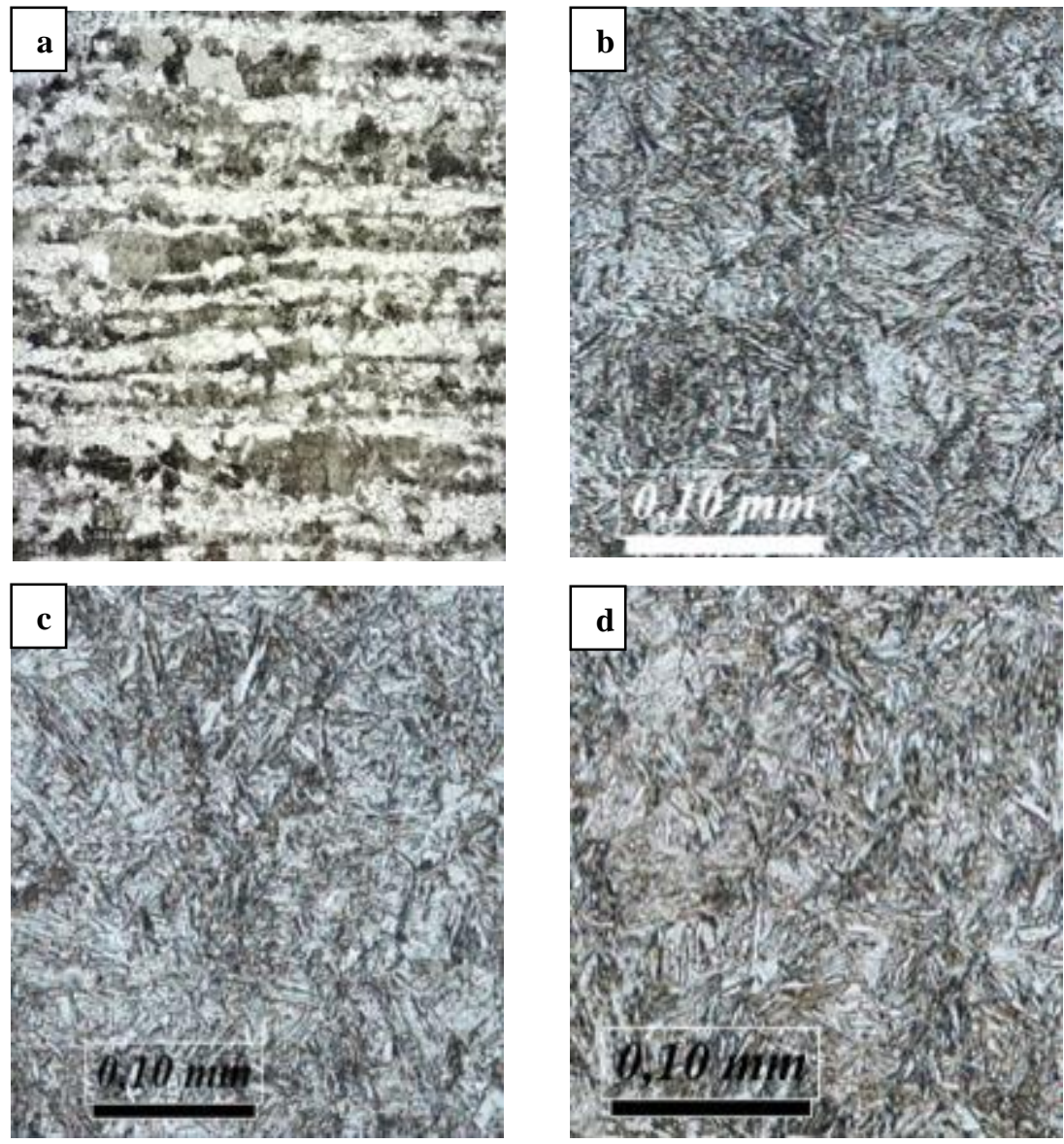

Gambar 5. Struktur Mikro (a) Baja C-Mn (b) Hasil Quenching Ty: $870{ }^{\circ} \mathrm{C}$. (c) Hasil Quenching Dan Tempering $\mathrm{T} \gamma 870^{\circ} \mathrm{C} \mathrm{T}_{\text {tem }} 125^{\circ} \mathrm{C}$ (d) Hasil Quenching Dan Tempering $\mathrm{T} \gamma 8^{\circ} 0^{\circ} \mathrm{CT}_{\text {tem }} 175^{\circ} \mathrm{C}$.

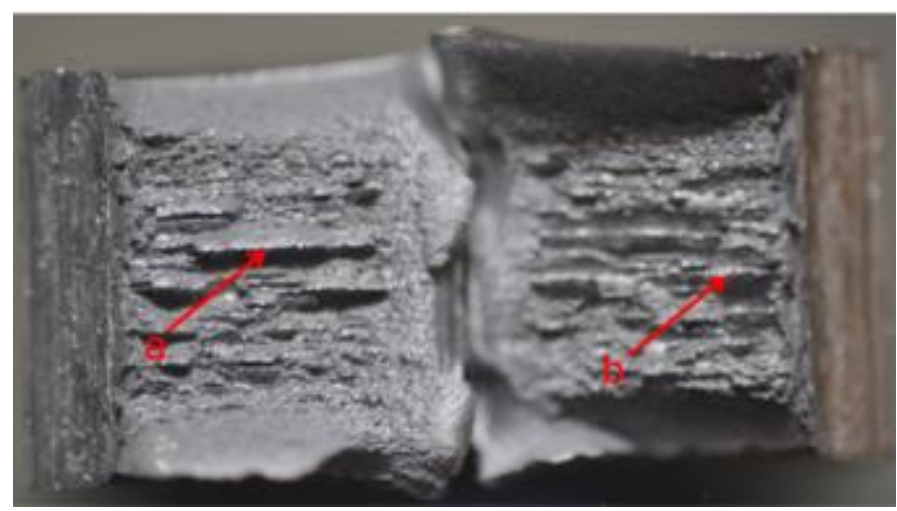

Gambar 6. Bentuk Patahan Baja C-Mn Tanpa Perlakuan Panas 


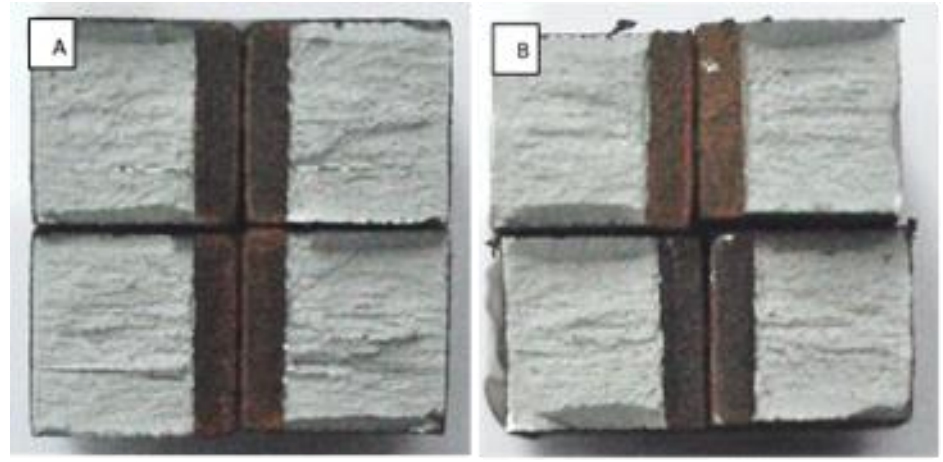

Gambar 7. Bentuk Patahan Baja C-Mn Setelah Dilakukan Proses Quenching Dan Tempering

\section{KESIMPULAN}

Nilai kekerasan diatas 400 BHN pada baja banyak digunakan sebagai baja tahan peluru, dari 6 specimen pengujian dengan berbagai variasi temperatur austenisasi dan tempering didapatkan nilai kekerasan diatas 400 BHN menandakan baja C-Mn lokal dapat memenuhi syarat menjadi baja tahan peluru (armor). Perubahan struktur mikro terjadi pada baja C-Mn setelah proses quenching dan tempering, struktur mikro berbentuk jarum-jarum kecil yang tersusun secara acak mendominasi keseluruhan struktur mikro (martensite). Struktur mikro martensite ini yang menyebabkan baja menjadi keras namun getas, foto fraktografi menunjukan juga hasil patahan bersifat patah getas.

\section{UCAPAN TERIMA KASIH}

Penulis mengucapkan banyak terima kasih kepada KEMENRISTEKDIKTI yang telah mendukung kegiatan penelitian ini melalui dana Hibah Penelitian Dosen Pemula tahun anggaran 2017.

\section{DAFTAR PUSTAKA}

[1] Darwanto, H. 2015. RPJM 2015-2019 Bidang Pertahanan. Melalui http://www.kemhan.go.id/kemhan/?pg=73\&id=1625. Diakses 12 Juli 2017.

[2] Pindad. 2014. Kendaraan Tempur Ringan, www.pindad.com, diakses 17 Juli 2017.

[3] Dimeski, D. \& Srebrenkoska, V, 2014. "The Role Of Contemporary Ferrous And NonferrousMaterials In Ballistic Protection Of Military Vehicles", Prociding VI ${ }^{\text {th }}$ International Metallurgical Congress. Ohrid.

[4] G. Magudeeswaran, V. Balasubramanian, S. Sathyanarayanan, G. Madhusudhan Reddy, A. Moitra, S. Venugopal, G. Sasikala, 2010. "Dynamic Fracture Toughness of Armour Grade Quenched and Tempered Steel Joints Fabricated Using Low Hydrogen Ferritic Fillers", Journal of Iron and Steel Research International, 17 (5): 51 - 56.

[5] Bernetič, J., Vuherer, T., Marčetič, M., \& Vuruna, M, 2012. "Experimental Research On New Grade of Steel Protective Material for Light Armored Vehicles", Journal of Mechanical Engineering, 58 (6): 416-421.

[6] Callister, W. D. Jr.(2007). An Introduction Material Science And Engineering seven Edition. Canada: John Wiley \& sonc, inc.

[7] W.S. Lee, T.B. Wu. 1999. "Mechanical properties and microstructural features of AISI 4340 highstrength alloy steel under quenched and tempered conditions", Journal of Materials Processing Technology, 87: 198-206.

[8] Jena, PK., Mishra, B., Rameshbabu, M., Babu, A., Singh, AK., Kumar, KS., Bhat, TB., (2010), Effect of Heat Treatment on Mechanical and Ballistic Properties of a High Strength Armour Steel. International Journal of Impact Engineering, 37: pp. 242-249.

[9] Mishra, B., Jena, PK., Ramakrishna, B., Madhu, V., Bhat, TB., Gupta, NK., (2012), Effect of tempering temperature, plate thickness and presence of holes on ballistic impact behavior and ASB formation of a high strength steel. International Journal of Impact Engineering, 44:pp. 17-28. 